\title{
San Agustín y las transformaciones de la mirada escéptica. La figura de Proteo en Contra Academicos
}

\author{
Claudio CÉSAR CALABRESE* \\ Universidad Panamericana (México) \\ ccalabrese@up.edu.mx
}

\begin{abstract}
Resumen
Este artículo estudia la transformación de las bases del escepticismo antiguo en el pensamiento agustiniano; para presentar el proceso se parte de la crisis que supuso la ruptura con experiencia maniquea, se distingue su preocupación y consideración sobre el modo y los límites del conocimiento y se analiza la función de la imagen mítica de Proteo en Contra Academicos; esta imagen permite ponderar la capacidad de la representación mítica como contrafuerte del carácter discursivo del saber humano. Mediante este recurso, san Agustín afirma que la razón no puede quedar aislada de otros modos complementarios de comprensión, hace propio el núcleo de la actitud escéptica y amplía la noción de racionalidad para la filosofía cristiana.
\end{abstract}

Palabras clave: joven san Agustín, maniqueísmo, escepticismo académico, proteo, filosofía cristiana.

\section{Saint Augustine and the transformations of the skeptical gaze. The figure of Proteus in 'Contra Academicos'}

\begin{abstract}
This paper studies the transformation of the foundations of ancient skepticism in Augustinian thought; to present the process we start from the crisis that led to the break with Manichaean experience, we distinguished their concern and consideration about the mode and limits of knowledge and analyzed the function of Proteo's mythical image in Contra academicos; this image allows us to weigh the capacity of mythical representation as a buttress of the discursive character of human knowledge. Through this resource, St. Augustine affirms that reason cannot be isolated from other complementary modes of understanding, appropriates the core of the skeptical attitude and broadens the notion of rationality for Christian philosophy.
\end{abstract}

Key words: young st. Augustine, manichaeism, academic skepticism, proteus, christian philosophy.

\footnotetext{
* $\quad$ Doctor en Letras por la Universidad del Salvador (Argentina); Doctor en Filosofía por la Universidad de Barcelona (España). Profesor - Investigador de la Universidad Panamericana (México, Campus Aguascalientes). Publicaciones recientes son el libro titulado Mito, conocimiento y acción. Continuidad y cambio en los procesos culturales (2019); y el artículo "Presencias órficas en los argumentos para la comprensión de Dios. Stromata V de Clemente de Alejandría" (2019).
} 


\section{INTRODUCCIÓN}

En nuestro trabajo se hace un seguimiento de la transformación que san Agustín operó en las bases del escepticismo antiguo; este proceso echó raíces en su biografía: la crisis de la experiencia maniquea se presentó en el momento en que a san Agustín se le hizo manifiesto que la razón no podía aprehender la esencia de lo divino, tal como afirmaban los maniqueos. Ello tuvo dos consecuencias: por un lado, la ruptura con los seguidores de Mani, con la crisis tanto psicológica como espiritual que significó y, por otro, la afectación de sus convicciones acerca de la certeza del conocimiento, con la dificultad que supone en el progreso filosófico. Aquella crisis, en sustancia, instaló la inseguridad de distinguir algo como conocido de su mera apariencia o, en otros términos, si es posible que haya algo en nosotros que tenga una naturaleza diversa de nuestras propias impresiones subjetivas, y su consecuencia inmediata, en forma de pregunta: ¿es posible percibir la realidad tal como es?

En efecto, el escepticismo helénico consistió fundamentalmente en declarar el carácter subjetivo del saber, mediante la anulación de toda afirmación que se presente como válida; en consecuencia, nada es seguro o constante. En esta primera etapa, el escepticismo no desarrolló una teoría sobre la duda, sino que expresó la irresolución de afirmar o negar algo, es decir, se mantuvo igualmente indiferente a una y a otra. En el presente artículo, la actitud de san Agustín es interpretada como respaldo metodológico al escepticismo, a partir del asentimiento previo de la fe; estamos de acuerdo, en efecto, con Harding (2003) y Kirwan (1983) cuando afirman, con distintos argumentos, que el lema agustiniano fides quarens intellectum es fruto de su escepticismo limitado: la razón librada a sus propios medios, sin el concurso de la fe, es incapaz de conocer la verdad. Esto implica tomar distancia de tres posturas clásicas de orden epistemológico, que ponen más atención a una perspectiva "eudemonística", en consonancia con De beata vita, algunos cuyos representantes son Holte (1962: 73-110), Neiman (1982) y Harding (2006). En esta línea de discusión, en la que es necesario probar la correlación entre la verdad y las verdades, el símil de Proteo conlleva nuevas posibilidades interpretativas (Bochet, 2009): sus transformaciones y las dificultades para atraparlo y obtener conocimiento no hablan ya a favor del escepticismo, sino de la noción platónica de participación (Boersma, 2016a: 177-183; Smalbrugge, 1990). El recurso del símil de Proteo permitió a san Agustín considerar que la razón no puede quedar aislada de otros modos complementarios de comprensión; aquí el Hiponense se refiere específicamente al papel del mito como contrafuerte del carácter discursivo del saber humano. Por ello, el escepticismo da un giro impensado respecto de su expresión antigua, pues, con san Agustín, 
significará que una razón, que ya no queda librada a sus propios recursos discursivos, es capaz de conocer, aunque consciente de que sus logros son siempre provisorios.

Daremos los siguientes pasos para mostrar nuestra hipótesis: 1) Ubicación del Contra Academicos en el contexto de los diálogos de san Agustín; 2) la crisis de nuestro autor con el Maniqueísmo y su aceptación del escepticismo académico; 3) la estructura del diálogo Contra Academicos; y 4) el símil de Proteo en la constitución de la nueva racionalidad que aporta el cristianismo. Finalizo con unas breves conclusiones.

1. CONTRA ACADEMICOS EN EL CONTEXTO DE LOS DiÁlogos DE SAN AgUSTÍN $^{1}$

Esta obra pertenece a los escritos de Cassiciaco, junto con De ordine y Soliloquia, que fueron concebidos y finalizados entre los años 386 y 387, es decir, en fecha anterior a su bautismo, acontecido el 24 abril de 386; a esta época pertenece también De magistro, iniciado en Cassiciaco, pero concluido en Tagaste en 389, y De libero arbitrio, que también expresa las preocupaciones de este tiempo, aunque fue escrito un poco después, en Roma, en el año 388, y sus libros II y III finalizados en una fecha anterior a su consagración episcopal, es decir, ya ordenado presbítero [Retractationes 9. 1] (Fuhrer, 1997: 3-4; Catapano, 2011: ix-x). ¿Quién era san Agustín en esta época? En principio, simplemente Agustín, un joven y brillante profesor de retórica, que había renunciado recientemente a su cátedra en Milán; un intelectual cristiano todavía no bautizado, como vimos poco más arriba; un maestro responsable de una comunidad de oración y estudio, aplicada a la reflexión filosófica y a la lectura y comentario de las Escrituras y de Virgilio².

La filosofía cristiana es entendida normalmente por las relaciones más o menos problemáticas que, en su seno, los filósofos o los teólogos establecen entre fe y razón o entre teología y filosofía; se ha fijado, de hecho, una sinonimia entre estos binomios, aunque el segundo no resulta completamente correcto, porque algunas escuelas, como la platónica, la aristotélica y sus respectivas tradiciones, ofrecen una teología como culminación de su filosofía (de Libera, 1990: 155; Albornoz Olivares, 2018: 96). Sin embargo, el trasfondo de esta distinción, de manera independiente de

1 En Retractationes 1. 1, san Agustín también se refiere a la obra como De academicis, título que refleja más plenamente la búsqueda agustiniana (Bermon, 2009).

2 Es casi seguro que los extremos de la permanencia de la comunidad de oración y estudio en Cassiciaco fueron de septiembre de 386 hasta principios de marzo del año siguiente, es decir, desde su conversión definitiva hasta su bautismo en Milán (Mathews. 1980: 39-51). 
cómo se la entienda, es de origen medieval y más específicamente tomista (Grant, 1986: 70; Mendoza, 2018; Goutierre, 2009), e intenta repensar, desde la raíz, la filosofía tal como había sido recibida de los antiguos. Obviamente no encontramos esto ni en la Antigüedad Tardía ni en la Temprana Edad Media; razón por la cual, los pensadores de aquellas épocas no tienen necesidad de distinguir entre estas nociones: ellos piensan en términos de problemas, es decir, de preguntas, y no primariamente de soluciones, cuyo modelo es, básicamente, el diálogo socrático. Por esta razón, san Agustín no se planteó la continuidad con la filosofía o, de manera más general, con la cultura grecolatina, porque está existencialmente inmerso en ella. La definición clásica de sabiduría (sapientia) como conocimiento de las cosas humanas y divinas (rerum humanarum et divinarum) muestra un interés filosófico por lo divino, que no reclama la necesidad de iniciar una reflexión sobre las relaciones entre razón y revelación (Brachtendorf, 2008). Por ello consideramos que san Agustín, durante este breve pero intenso proceso, que va desde el encuentro con la filosofía neoplatónica en Milán hasta su ordenación episcopal, desarrolló una obra que encontró en el diálogo su instrumento natural (no en vano no volverá sobre este género literario-filosófico) y que forjó un nuevo modelo de racionalidad, el cual entrará en juego en la interpretación de las Escrituras, como será evidente - por sus alcances filosóficos y teológicos- en De Genesi ad litteram (Velásquez, 2007: 215-216).

\section{LA RUPTURA CON EL MANIQUEÍSMO Y LA CRISIS CONSECUENTE}

Dentro del complejo marco religioso que hallamos en el Imperio Romano entre los siglos II y V, el fenómeno del Maniqueísmo ocupó un lugar determinante. Este movimiento religioso, que había nacido en el siglo III d. C., en la Mesopotamia de cultura persa, se extendió desde Europa hasta China, rivalizando con el Zoroastrismo, el Cristianismo, el Budismo y el Islam, originando diversas fusiones culturales. Nuestro interés se centrará, dentro de este amplísimo arco, en la parte Occidental del Imperio, es decir, según el modo específico en que san Agustín recibió esta tradición (Calabrese, 2017; Koenen, 1978; Brown, 1969).

¿Qué relato del mito maniqueo conoció san Agustín? "La Enseñanza de la Luz" es la doctrina maniquea que explica la constitución del universo; este se dividió desde su origen, en dos principios eternos, increados e irreconciliables: Luz y Oscuridad. El Reino de la Luz se encontraba en el Norte, tendía hacia arriba, y se extendía infinitamente hacia el Norte, Este y Oeste y fue gobernado por el Padre de la Grandeza, que en Persia se identificó con Zurvan (Van Lindt, 1992: 3-17). La visión gnóstica en general se expresa de una manera que es siempre indicativa y, por ello, más 
flexible que el discurso racional para ponderar los conocimientos hechos vivencias. Se pone de manifiesto, por un lado, la universalidad del mensaje $y$, por otro, la capacidad de encontrar en todas las culturas su vehículo de predicación (García Bazán, 2000: 170). El Reino de la Oscuridad (Hyle) se encuentra en el sur y se extiende infinitamente, aunque solo hacia el Sur, gobernado por el príncipe de la oscuridad, y se manifestaba como cinco "mundos": humo, fuego, tormenta, barro y oscuridad. Los demonios se dividieron en dos sexos, y su existencia se caracterizó por la guerra constante y la procreación. Cada mundo de la oscuridad fue gobernado por un Arconte: un demonio, un león, un águila, un pez y un dragón. Debido a la inquietud que le es inherente, el Reino de la Oscuridad siempre pugnaba por aproximarse a las fronteras del Reino de la Luz y dominarlo. En algún momento, en medio del caos que reinaba en la oscuridad, a causa de sus incesantes guerras, el príncipe de la oscuridad quedó en la parte superior de su reino, desde donde pudo observar el resplandor del Reino de la Luz $y$, en ese instante, deseó poseerlo. Los dos principios que están frente a frente son irreductiblemente opuestos entre sí, pero tienen en común que son eternos e igualmente potentes. Esto significa que el mal es únicamente responsabilidad de la Oscuridad (no se trata de ausencia de luz, sino de su rechazo). Debemos tener presente, sin embargo, que podemos suponer un origen que el propio mito silencia: la prehistoria en la que el Espíritu del Bien y el Espíritu del Mal era uno solo capaz de desdoblamiento, una unidad de gemelos que se diferenció sin menoscabo de su libertad: una permaneció divina y la otra vaciada de divinidad (García Bazán, 2000: 172173; Giuffré Scibona, 2001).

El Padre de la Grandeza comprendió que era necesario defenderse de las fuerzas de la Oscuridad. Pero todo en su Reino estaba dispuesto para la paz; por lo que el Padre mismo decidió ir a la batalla. Para ello, creó tres Evocaciones de sí mismo. En la primera, el Padre evocó al "Gran Espíritu" o "Sabiduría" (Sofía). El Gran Espíritu engendró a la "Madre de los Vivientes", y ésta, al "primer hombre". El primer hombre y sus cinco hijos (fuego, viento, agua, luz y éter), que fueron las "cinco prendas de la Luz" que componían su armadura, descendieron a la Oscuridad para enfrentarla. Mientras luchaban en el Reino de la Oscuridad, el hombre primordial logró cortar las raíces de los cinco árboles de la Oscuridad, evitando así un mayor crecimiento del mal. Sin embargo, los demonios finalmente lo derrotaron: devoraron su armadura (sus hijos) y quedó desmayado en el campo de batalla. La oscuridad de la materia devoró la luz del hombre primordial. Con el tiempo, esta Luz se fue deteriorando por el contacto con la materia, al punto que olvidó su origen y su naturaleza; pero también la materia se vio modificada por el contacto con la Luz, al punto de no poder existir independientemente de ella. Cuando el hombre primordial 
recuperó la conciencia, elevó siete oraciones al Padre de la Grandeza, invocando su ayuda. El padre escuchó su oración y realizó la Segunda Evocación de sí mismo, "El Amigo de las Luces", que convocó al "Gran Arquitecto" y éste al "Espíritu Viviente", quien con sus cinco hijos descendió en la oscuridad para regresar a la luz al primer hombre: le extendió la mano derecha, lo alzó de la oscuridad, y se lo llevó de nuevo a la luz. Pero las partículas de la luz de su alma y de sus cinco hijos quedaron en la oscuridad, a la espera de la redención. El Espíritu Viviente regresó luego al Reino de la Oscuridad y llevó la guerra contra sus demonios; con sus cuerpos creó el mundo y liberó parte de la Luz que estaba prisionera. Por último, separó la luz que estaba dentro del Reino de la Oscuridad en tres partes, de acuerdo con su grado de mezcla con la materia. Con la luz sin mancha creó el sol y la luna; con la luz que había sido ligeramente contaminada, creó las estrellas. También creó tres grandes Ruedas para la redención de esa Luz que la materia retuvo: la rueda de fuego, la rueda de agua y la rueda de viento. Se había creado el mundo como un mecanismo para la redención de la luz restante. Antes que la gran máquina universal pudiera ponerse en marcha, el Tercer Enviado creó un camino hacia el Reino de la Luz. Lo hizo bajo la forma de la "Columna de la Gloria" o "Columna de Luz”, que puede verse en el cielo nocturno como la Vía Láctea. Cuando la máquina del universo se puso en marcha, las partículas purificadas de luz ascendían a través de la Columna de la Gloria de la luna; de allí la luz redimida pasaba a un lugar llamado el "Nuevo Eón", sitio diseñado por el Gran Arquitecto. El Nuevo Eón era consustancial con el Reino de la Luz, pero se mantendrá al margen de ella hasta el último día (van Oort, 2008).

La Materia quebró los vínculos del Primer Hombre con la sabiduría del origen. Los ángeles celestes rogaron a la tríada divina para que enviase un salvador que les devuelva la conciencia; es enviado Jesús, cuyo primer fin es salvar su alma, para liberar a Adán del demonio y de la carne, instruyéndolo sobre el verdadero conocimiento (Polotsky, 1996: 74). Todo el interés se centra ahora en el Alma del Mundo, pues en el devenir cósmico se desarrolla el proceso de auto-liberación divina. La reintegración al SíMismo alcanzará su fin cuando toda la Luz esté congregada, cuando lo múltiple tenga conciencia de la Unidad. Con anterioridad, el mundo alcanzará su fin; esto estará precedido por las aflicciones que aparecen en la apocalíptica de la religión irania, del último judaísmo y del cristianismo. Finalmente vendrá el Gran Rey y realizará el último juicio, en el que lo bueno será separado de lo malo, que quedará inmovilizado en la profundidad. El mito no aclara si la totalidad de las partículas de Luz alcanzarán la liberación o algunas quedarán prisioneras en aquella materia arrojadas a la profundidad. 
Este mito, que san Agustín conoció de primera mano (van Oort, 2010; Calabrese, 2017), nutrió los conceptos de Dios y de naturaleza, mientras transitó por el maniqueísmo. ¿Qué lo atrajo para permanecer auditor durante nueve años? Seguramente tuvo un papel fundamental la promesa de una ciencia de la naturaleza en estado puro, a partir de una lógica de los contrarios que expresan los relatos míticos en "La enseñanza de la Luz". La sed de sabiduría que se había desatado con la lectura del Hortensio de Cicerón parecía saciarse en los relatos y enseñanzas de los discípulos de Mani. El dualismo radical de principios (luz y oscuridad) podía explicar y superar el conflicto de la razón en el conocimiento de la naturaleza. Esta distinción entre sustancias le pareció científica a san Agustín porque estaba fundada en el principio de no contradicción. De hecho, padeció durante su juventud la incapacidad de encontrar una explicación satisfactoria al grave tema del mal. Los maniqueos parecían explicarlo al identificar esta cuestión moral con la explicación puramente lógica de elementos físicos contrarios y enfrentados. Fue una respuesta simple a una cuestión inquietante, de la que se sentirá progresivamente insatisfecho, aunque le llevará casi diez años comprender su inconsistencia (Wills, 2003: 61-63). Como leemos en Confesiones (5. 8), san Agustín advirtió que la explicación de la naturaleza que proponía Mani era insostenible a partir de los conocimientos de su época; continuar con los maniqueos únicamente era posible si Agustín creía en la explicación de Mani, contra la ciencia, contradiciendo la promesa de acceder a la verdad mediante la razón y no a través de la autoridad.

Si bien estaba decepcionado por aquella promesa incumplida de primero saber y luego creer, la crítica maniquea a las inconsistencias de la Escrituras le impidieron el regreso al cristianismo que había recibido de su madre Mónica; sin embargo, esta situación comenzará a cambiar a partir del trato asiduo de san Ambrosio, en Milán, pues en sus predicaciones expuso un modo espiritual de comprender el Antiguo testamento (Conf. 5. 23). San Agustín, a la luz de sus conocimientos de la doctrina escéptica, mediados por Cicerón, se aleja de los maniqueos, de acuerdo con la doctrina de lo probable, aunque no implicó volver a la fe católica, pues no podía identificar su conocimiento con la certeza; por ende, solo podía suspender el juicio a la manera académica: "En consecuencia resolví quedarme como catecúmeno de la Iglesia católica... mientras no brillara alguna certeza (aliquid certi) que me diera seguridad" (Conf. 5. 25).

Ya no era un maniqueo, pero tampoco un cristiano convencido; continuaba bajo el influjo de aquel materialismo radical, de su concepción del mundo y del mal como algo ajeno a la voluntad (Conf. 7. 1-6). El trasfondo todavía era Cicerón y su postura de una sabiduría inteligible e incorrupti- 
ble, forjada, para poder cumplir con esta característica, antes que la naturaleza sensible, pero sin que pudiera estar fuera de ella: por un lado, la naturaleza queda muda ante el carácter lógico de la fundamentación moral (aprendizaje de evidente cuño escéptico) y, por otro, la creencia materialista de Dios no podía ser fundamentada por la misma razón. San Agustín replanteó estos problemas a la luz del neoplatonismo, que le brindó las herramientas intelectuales para concebir a Dios y al alma como realidades incorpóreas conocidas por el alma (Conf. 7.16). Así comprendió que lo inmutable es más perfecto que lo mutable y que, en consecuencia, Dios no podía mutar con la materia (Wills, 2003: 63-66). Esta distinción entre ser absoluto (Dios) y el ser relativo de lo creado le permitió esbozar sucesivas explicaciones sobre el tema del mal, mediante la noción de privación; al mismo tiempo, la noción platónica de Pronoia (Timeo 53), en lectura estoica, permitía sostener filosóficamente la noción teológica de Providencia o gobierno divino que transforma los males finitos en un medio para realizar el Bien (Conf. 7. 22). Si bien esto demostraba la falsedad del maniqueísmo, faltaba fundamentar la capacidad de la razón para conocer lo real.

\section{LA ESTRUCTURA DEL DIÁLOGO CONTRA ACADEMICOS}

El diálogo se desarrolla en una alquería (villa, 3. 9, o rus 3. 34) de Cassiciaco, cuya localización exacta se desconoce, pero se deduce del mismo texto que se encontraba próxima a Milán. Además de la dedicación a la oración y al estudio, el grupo se aplicaba a las labores agrícolas (1.15) y a las tareas domésticas (2. 25). Las conversaciones se prolongan a durante seis días: dos unidades de tres, con un intermedio de una semana, en la que se dedican a tareas rurales (2.10). La primera conversación se desarrolla al aire libre y finaliza cuando comienza a oscurecer (1. 10); la segunda, cuando comienza el atardecer (1.15) y la tercera, cuando comienza a amanecer y finaliza a la hora del almuerzo (1.25); la discusión del cuarto día se sostiene en la campiña, después del almuerzo hasta el atardecer (2. 24); la quinta jornada tiene lugar bajo la sombra de un árbol, durante las dos últimas horas de luz (2. 25); a causa del mal tiempo, le sexta y última jornada se cumple en los baños hasta que anochece (3. 44). Por Retr. (1. 1) sabemos que se había dedicado a la paz de la vida cristiana (ad christianae vitae otium) para alejar (amovère) de su ánimo los argumentos que ponían en duda las certezas de encontrar la verdad y dejar atrás la incertidumbre y la oscuridad (obscura et incerta). Es importante para nuestro trabajo que, unos cuarenta años después de la experiencia en la finca al pie de Los Alpes, san Agustín considere que el objetivo de la obra era terminar con la incerti- 
dumbre acerca de la posibilidad de conocer; esta perspectiva autobiográfica implica también remediar los efectos psicológicos negativos de la experiencia maniquea, que lo había conducido al estado de escepticismo que ahora rebate.

Contra académicos, desde el punto de vista compositivo, está dividido con claridad en dos partes: por un lado, el Libro I y, por otro, el bloque que constituyen los Libros II-III; ambas partes están estructuradas en espejo: una exhortación a Romaniano a vivir filosóficamente, seguida de tres días continuados de discusiones. El Libro I está centrado en la disputaio entre Licencio y Trigecio en torno a la felicidad como búsqueda de la verdad (investigar con la confianza de encontrar) y los Libros II y III presentan las conversaciones sucesivas de san Agustín con ambos discípulos; estos dos libros se esfuerzan en demostrar que es posible alcanzar conocimientos ciertos en lo que atañe a la filosofía, concebida como deseo de una sabiduría que no puede desentenderse — para ser tal — de la verdad (Moreschini, 2013: 965-966).

La plática del Libro I gira en torno a la pregunta: ¿es posible ser feliz buscando la verdad sin hallarla? Se denomina "vivir felizmente" a ordenar la propia vida según la parte mejor del hombre, es decir, la mente o razón. “QQuién dudó - dije- alguna vez que lo óptimo del hombre es aquella parte del ánimo, a cuyo dominio conviene se sometan las otras que hay en el hombre? Y ésta es, para que no me pidas otras definiciones, puede llamarse mente o razón (mens aut ratio)" (I. 5). San Agustín y Alipo son los jueces de las respuestas de Licencio, quien considera que se puede ser feliz buscando sin encontrar, y de Trigecio, quien sostiene lo contrario; al mejor estilo platónico, el diálogo no alcanza una respuesta satisfactoria, pero ha logrado una precisión importante: es indispensable buscar la verdad para alcanza la felicidad y la filosofía es la actividad más apropiada para hacerlo posible. El libro finaliza con la propuesta de san Agustín a Licencio para que prepare la defensa de la postura escéptica de los académicos, que él tratará de invalidar.

En el Libro II, encontramos un segundo prólogo, en el que se presentan las barreras de orden psicológico para alcanzar el conocimiento; en efecto, allí se hace referencia a la facilidad con que las personas, que alguna vez se sintieron inclinadas a buscar la verdad, la abandonan por las preocupaciones de la vida cotidiana o por pereza mental (2.1.1) o por haber perdido la esperanza de alcanzar lo que se busca (desperatione inveniendi) o por creer que ya se ha alcanzado la verdad. Desde esta perspectiva, que mantiene alejada a la inmensa mayoría de la gente del saber, los argumentos escépticos parecen irrefutables. El principal problema de Romaniano es el gran número de preocupaciones propio de su posición socio-económica: es necesario rogar por la ayuda de la Providencia, que dispone de los 
acontecimientos cotidianos con una finalidad inalcanzable al entendimiento humano, para que pueda gozar de su libertad y dedicarse a la actividad filosófica. San Agustín reconoce el talante filosófico de Romaniano, tal como se reveló en los proyectos comunes de vida teorética y especialmente en ciertas lecturas: libri quidam pleni (2. 5), es decir, "ciertos libros plenos o henchidos (de significado)", a los que compara, en sus efectos, con los buenos perfumes de Arabia. Es muy probable que estos libros sean los mismos que recuerda en Confesiones (quidam platonicorum libri, 7. 13 y 8 . 3) y que, tal vez en parte, podrían coincidir con los que menciona en $D e$ beata vita (Plotinipaucisimi libri; 1. 4). Como advierte Moreschini (2013: 968), es difícil establecer el contenido de aquellos libros; podemos conjeturar textos plotinianos (I. 6, III, 2-3 y V. 1) y extractos de obras de Porfirio, con seguridad De regressu animae y Sententiae, tal vez en la traducción de Mario Victorino, que san Agustín cita (Civ. X. 32), para refutar la teoría de la metempsicosis que sostiene su autor.

Exponemos ahora la doctrina de los académicos, según el orden argumentativo que introduce san Agustín, a pedido de Licencio, como introducción a la discusión que, inmediatamente después, sostendrán ambos. Los pasos de dicha argumentación son los siguientes (2. 11-12): a) el hombre no puede llegar a la ciencia, al menos, de aquello que concierne a la filosofía; b) a pesar de lo anterior, es posible para el hombre alcanzar la sabiduría, aunque sin dar asentimiento a nada en particular, a partir de la afirmación de que todo es incierto con abundancia de argumentos; c) partían de la afirmación del estoico Zenón, según la cual únicamente puede tenerse por verdadera aquella representación que ha sido impresa en el alma por el objeto que la origina: lo verdadero puede ser comprendido por aquellos signos que no pueden tener lo que es falso; por consiguiente, dichos signos no pueden encontrarse en nuestras percepciones (Acad. 2. 12); d) ¿Qué queda del sabio, si no es posible que afirme algo? El sabio, entonces, buscará lo verosímil (veri simile) ${ }^{3}$, lo que constituirá propiamente su acción.

San Agustín considera, entonces, que la gnoseología atribuida a Zenón buscó establecer qué puede ser objeto del acto del percipere o comprehendere; ambos verbos, que son utilizados como sinónimos, designan una operación de conocimiento muy particular; Cicerón echó mano del sustantivo correspondiente, comprehensio, para traducir el sustantivo katalepsis, originado a partir del verbo katalambano, con el significado de "tener, apoderarse de". En Luculus (47. 145), el Arpinate señala que el término fue acuñado por Zenón y etimológicamente expresa la captura de una presa,

3 Este giro se presenta, a lo largo del Libro II, con el sentido de conocimiento aproximativo, en los siguientes pasajes: 12, 15, 16, 20, 26, 27, 30, 31 . 
como algo que está aferrado, es decir el visum, que traduce el griego phantasia (representación); en relación con lo anterior, encontramos la precisión agustiniana de los signa o "signos" de la verdad: para que una representación pueda ser percibida es necesario que esté dotada de "características peculiares" (notae, en el vocabulario agustiniano), que las distingan de percepciones falsas. A partir de Arcesilao, los representantes de la Academia objetaron esta distinción, pues no es posible vincular las representaciones con los signos y llegaron a la conclusión ya conocida: nada es comprensible; esta es la tesis de la akatalepsia, que san Agustín, siguiendo la traducción de Cicerón, expresa como nibil posse percipi (Moreschini, 2013: 972).

Luego de plantear los fundamentos del escepticismo académico, san Agustín inicia la discusión con su discípulo; su primera objeción está dirigida hacia el concepto de "verosímil": si se ignora la verdad, es imposible afirmar el concepto de verosimilitud. San Agustín considera que dos son las tesis centrales del escepticismo académico que han sido discutidas: a) la imposibilidad de conocer la verdad con certeza; b) en consecuencia con lo anterior, negar asentimiento a toda representación. El Libro tercero (22) presenta la superación del escepticismo, durante el sexto día de discusiones: "Dos cosas dicen los académicos, contra las cuales nos hemos propuesto prevalecer: 'nada puede ser percibido'; 'a ninguna cosa debe darse asentimiento"'. El pasaje en que san Agustín trata el tema de la percepción resulta oscuro; presentaremos en texto latino, luego nuestra traducción e interpretación:

Nihilne prorsus dicitis posse comprehendi? Hic evigilavit Carneades: nam nemo istorum minus alte quam ille dormivit, et circumspexit rerum evidentiam. Itaque credo, secum ipse, ut fit, loquens: Ergone, ait: Carneades, dicturus es nescire te utrum homo sis, an formica? Aut de te Chrysippus triumphabit? Dicamus ea nos nescire quae inter philosophos inquiruntur; caetera ad nos non pertinere, ut si in luce titubavero quotidiana et vulgari, ad illas imperitorum tenebras provocem, ubi soli quidam divini oculi vident: qui me etiam si palpitantem atque cadentem aspexerint, caecis prodere nequeant, praesertim arrogantibus, et quos doceri aliquid pudeat.

¿Dicen que nada puede traducirse? Aquí despertó Carnéades, pues ninguno de ellos durmió menos profundamente que él, y observó la evidencia de las cosas. De este modo, creo que halando consigo mismo, como sucede, dijo: ¿luego, Carnéades, vas a decir que no sabes si eres hombre u hormiga? ¿O triunfará Crisipo sobre ti? Digamos que nosotros no conocemos estas cosas, que son indagadas entre los filósofos; lo demás no nos atañe, de modo que si dudas a la luz cotidiana y corriente, apelaré a aquellas tinieblas de los ignorantes, donde únicamente ven ciertos ojos divinos, los cuales, aunque me 
vieren vacilar y caer, no me pueden entregar a la irrisión de los ciegos y especialmente a los arrogantes, quienes no se avergüenzan de ser enseñados.

El sentido del pasaje parece ser que Carnéades se remite al sentido común (la "tiniebla de los ignorantes") y se ubica fuera de los problemas de la filosofía; si él mismo se engaña, los ciegos (los que siguen el sentido común), especialmente los argullosos, no podrán juzgar una doctrina que no queda comprometida por errores de orden práctico. Consideremos el orden en que se llega a esta postura. En el capítulo tercero del último libro, se discute si existe diferencia alguna entre el filósofo y el sabio; a la pregunta del maestro, responde su discípulo: "Entre el sabio y el aspirante a la sabiduría no hallo sino esta diferencia: las cosas que el sabio posee como hábito, el aspirante las tiene en el ardor del deseo" (3.5). Para que exista uno u otro es necesario dar lugar a la verdad y al error (distinguiéndolos); es evidente entonces que san Agustín considera que el núcleo de la tesis académica es que no es posible la percepción de la verdad y que su tarea consiste en hallarla, aunque todavía le resulte esquiva (3. 6). El discípulo, sin embargo, no está de acuerdo con la conclusión, pues no encuentra modo de diferenciar y concordar "creer que se sabe" y propiamente "saber"; la respuesta de san Agustín dice mucho sobre el método de la búsqueda: "No me desagrada que me contradigas tanto, porque o ninguno de los dos sabemos lo que decimos, y hemos de evitar semejante torpeza, o no lo sabe uno de nosotros, y tampoco conviene dejar la cosa así. A la tarde volveremos al tema. Yo creía que estábamos al cabo de la cuestión, cuando ahora me muestras los puños" (3. 6).

Por la tarde continúa la disputa entre maestro y discípulo, centrada en lo sustancial- en discernir si el sabio conoce la sabiduría y, más ampliamente, si es posible la existencia de alguien sabio; pregunta san Agustín: “'Te parece a ti que el sabio conoce o no la sabiduría?" (3. 9). A la respuesta afirmativa de Alipio, se encabalga la segunda pregunta:

Ahora, pues, te pregunto si puede darse un sabio. Pues, en caso afirmativo, podrá también conocer la sabiduría, y toda la cuestión entre nosotros está resuelta. Si, al contrario, sostienes que es imposible el sabio, entonces la cuestión primera no será si sabe algo, sino si alguien puede ser sabio (Acad. 3. 10).

Si bien la pregunta (al menos formulada en estos términos) excede la disputa sobre el escepticismo de los académicos, pues ellos consideraron que un hombre puede ser sabio, aunque el ser humano no posea un saber seguro; afirmaron, de hecho, que el hombre nada sabe (III. 4. 10). Sin embargo, no hay propiamente una ciencia de saberes falsos. Se hace evidente 
que los académicos se quedan sin camino para seguir, pues o reconocen que la sabiduría no es algo o que su noción de sabio simplemente no es razonable. "Y omitiendo estas cuestiones, convengamos en indagar si el hombre puede alcanzar la sabiduría, tal cual la describe la razón" (3. 10). Por ello, Alipio considera que no se ha logrado rebatir el parecer de los académicos, pues no se ha demostrado que sea posible la percepción verdadera. Para san Agustín ha quedado probado que no resulta sostenible la afirmación de que nada se puede conocer; por el contrario, se debe seguir discutiendo si se le debe prestar asentimiento a algo (3. 12); san Agustín propone trabajar no sobre la sabiduría, sino sobre la verdad: "Pero yo sostengo que debemos afirmar alguna cosa, esto es, la verdad" (Acad. 3. 12; Kenyon, 2018: 24-56).

Ahora bien: ¿cómo se alcanzará el asentimiento de la verdad? San Agustín presenta, en principio, la definición de Zenón: “.... sólo puede percibirse y comprenderse un objeto que no ofrece caracteres comunes con lo falso" (3. 18). El Hiponense responde que no es posible hallar un objeto cuyo conocimiento no tenga estas características y que, si se sostiene, convendría afirmar simple y directamente que el hombre no puede alcanzar la sabiduría. Sus argumentos y ejemplos de conocimientos indudables y accesibles también para quien no ha alcanzado la sabiduría se relacionan con los tres ámbitos propios de la filosofía: física, ética y dialéctica. De este modo, san Agustín ingresa directamente en las áreas en que los académicos justifican la imposibilidad de un conocimiento cierto: A) las diferentes opiniones de los sabios acerca, por ejemplo, del número de mundos; sea que se considere que es uno solo o que son diversos, ambas opiniones tienen la certeza de que su número es finito. B) Los engaños de los sentidos pueden ser reales, pero afirman al menos que hay una apariencia y esto es crucial para conocer el mundo como tal: las cosas son como parecen ser; en este sentido, el problema de la veracidad de los sentidos debe limitarse al hecho de la sensación misma. C) Las alucinaciones tampoco determinan la validez del conocimiento, pues las proposiciones son verdaderas o falsas en sí mismas y no por las condiciones de lucidez o delirio, en que pudieron formularse. D) Ante las paradojas lógicas, la dialéctica establece formas seguras de conocimiento; contra ellas, nada puede el uso sofístico de las paradojas, muy del gusto de los académicos.

En oposición a la afirmación de Zenón, san Agustín establece los fundamentos, a partir de los cuales el sabio puede conocer con certeza, es decir, dar asentimiento al conocimiento. Considera, en efecto, que no es posible que los Académicos no hayan advertido las limitaciones de su escepticismo y, por ello, propone una explicación acerca de su postura: las tesis del escepticismo están profundamente arraigadas a la época en que se generaron y deben comprenderse como parte del desarrollo de la filosofía 
de Platón; que el filósofo ateniense haya pensado en la existencia de dos mundos, uno inteligible (sitio de la verdad misma) y otro sensible (conocido por los sentidos), es decir, uno verdadero y otro semejante a lo verdadero o "verosímil" (2.37). Estos y otros conocimientos eran transmitidos, al interior de la Academia, en forma de iniciación, pues la persona que los recibiera debía estar con su alma purificada. Cuando Zenón ingresó a la Academia se lo mantuvo alejado de estos conocimientos secretos, hasta que las enseñanzas lo purificaran de la ponzoña recibida de otros maestros. Arcesilao, que ya estaba formado en una visión materialista de la realidad, decidió ocultar las doctrinas espirituales y realizar una refutación de las tesis de Zenón. Nacía así la Academia nueva. La filosofía de Crisipo dio nuevos bríos a la teoría de los corpúsculos de Zenón; ésta, a su vez, llevó, en el seno de la Academia, a la reacción de Carnéades, quien llamó "verosímil" o "probable" a los conocimientos, porque no podían establecerse con certeza.

A partir de estas conclusiones, san Agustín logra remover los obstáculos psicológicos que le había producido el escepticismo; esta remoción constituye el verdadero comienzo del programa filosófico del Hiponense, que consiste en asumir la sabiduría confiado en la autoridad de Cristo y en utilizar los instrumentos racionales del neoplatonismo, que conducen al acto de fe (Moreschini, 2013: 977-978).

San Agustín aceptó, por las razones biográficas que consignamos al principio, el desafío que representaba el escepticismo de la Academia Nueva; por esta razón buscó un fundamento seguro en su búsqueda de comprender la relación razón - verdad, tal como se manifiesta en la conciencia de sí mismo. Este hecho coloca el conocimiento que parte de la introspección más allá del alcance de la apariencia y lo vuelve inaccesible a la duda. Desde esta perspectiva, argumentó que la tradición platónica podría superar el desafío de la Nueva Academia, pues permitía plantear de manera renovada el problema de la adecuación del pensamiento al ser; por ello, la piedra de toque descansa en la gnoseología platónica, según la cual se conoce algo indirectamente mediante algo distinto conocido de manera directa. A partir de aquí, san Agustín pudo plantear que la oposición entre ser y apariencia, en la que se sostuvo el escepticismo, es propia de todo conocimiento. Por lo tanto, se conoce un objeto sensible externo a nosotros a través de una imagen que produce en nosotros, la que nos permite considerar la naturaleza de ese objeto (otra cosa fuera de esta supondría postular que el intelecto alcanza una visión directa del objeto). Consciente de ello, san Agustín pudo comprender a fondo que la postura escéptica implicaba algo más que negar la presencia de la razón en sus propias ope- 
raciones. De este modo, san Agustín delimitaba las posibilidades del escepticismo antiguo de plantear una división absoluta entre sujeto y objeto, ser y apariencia.

Esto resulta determinante para fundamentar que la mente en cuanto mente alcanza conciencia de sí misma con algo que es distinto del yo: reconocerse implica conocer una realidad objetiva diversa de sí misma. San Agustín consideró que en el pensamiento mismo se encontraba el vínculo entre la apariencia sensible y su fundamento en lo divino; en efecto, la conciencia de sí, tal como se muestra de manera directa, une en sí misma lo aparente y lo real y otorga a las apariencias un sentido positivo.

\section{El SÍMIL DE PROTEO}

Proteo es una deidad marina, cuya etimología hace referencia a su condición de "primogénito" de Poseidón, a la que se le atribuían dones proféticos, pero únicamente ponía esta capacidad a disposición de quien lo capturara; esta tarea no era en modo alguno sencilla, porque, en cuanto percibía que lo observaban, mutaba de forma para evitar ser capturado y obligado a profetizar. Homero, en el Libro IV (vv. 384 ss.) de La Odisea, lo presenta con sus características fundamentales: Menelao cuenta a su joven huésped, Telémaco, que Proteo habita la isla de Faro, ubicada frente al delta del Nilo y que aprendió de la hija de Proteo, Eidotea, cuya etimología remite a la idea de "representación" ("la imagen misma de la diosa"), que debía sujetar a la deidad y así obligarlo a que revelara a qué dioses había ofendido, a fin de aplacarlos con ofrendas y poder regresar a Esparta; en el momento en que Proteo sale del mar para dormir entre las focas de Poseidón, de las que era pastor, Menelao lo atrapó a pesar de que se transformó en león, serpiente, leopardo, cerdo, agua y árbol; como Menelao se mantuviera firme y no lo liberara, logró que respondiera a su pregunta y vaticinara.

¿Qué significado tiene este relato mítico en Contra academicos, en el contexto de la discusión sobre los fundamentos del escepticismo académico? Nuestra tesis es la siguiente: en este diálogo, Proteo expresa la imagen de la verdad, es decir los modos en que participan las imágenes temporales de la verdad inmutable; resulta claro que san Agustín vincula el carácter evasivo y metamórfico de Proteo con la noción platónica de imagen. El Hiponense asigna a la figura mítica un significado relevante, pues hace manifiesta la verdad y conduce a la persona hacia ella (Acad. 3. 13).

Debido a ello, vemos cómo surge el símil de Proteo en el diálogo. En consonancia con el modelo platónico, el diálogo agustiniano no ha avanzado hacia la afirmación o la negación del saber humano, pero sí ha afinado los medios para llegar a aquel discernimiento; el tema de fondo se 
plantea nuevamente (Acad. 3. 10): ¿es posible la existencia de alguien a quien podamos llamar sabio? Si la respuesta es positiva, ese alguien deberá conocer la sabiduría, sin que sea necesario continuar con la discusión; si, por el contrario, la respuesta es negativa, el tema ya no será si se puede alcanzar un conocimiento seguro, sino si alguien puede ser llamado sabio. Esta encrucijada la habían dispuesto los académicos, quienes afirmaron que un hombre puede ser sabio sin poseer ciencia, por lo que restan dos caminos intransitables: a) la sabiduría no existe o b) la noción de sabio no fue concebida por los académicos conforme a razón (sus conocimientos únicamente pueden ser considerados probables o verosímiles). Alipio entiende que los académicos no han quedado fuera de la discusión (Acad. 3. 11); en efecto, si ellos siguen firmes en su argumento, que descansa en la imposibilidad de saber si una percepción es verdadera, no es posible -en los términos militares a los que recurre san Agustín- desalojarlos de su posición.

El debate sobre la validez de la afirmación escéptica acerca de que la verdad no puede ser conocida tiene un punto de inflexión en el símil de Proteo, pues abre un espacio de comprensión acerca de la veracidad de las imágenes, cuya naturaleza es temporal y, en cuanto tal, material, con la pregunta: ¿es posible conocer la verdad de un ente material en permanente estado de cambio? Por ello, interpretamos esta obra de san Agustín como expresión de un respaldo metodológico al escepticismo, a partir del asentimiento previo de la fe; estamos de acuerdo con Harding (2003) y Kirwan (1983) cuando afirman, con distintos argumentos, que el lema agustiniano fides quarens intellectum es fruto de su escepticismo limitado: la razón librada a sus propios medios, sin el concurso de la fe, es incapaz de conocer la verdad. San Agustín sostiene el esquema platónico de la participación adaptado a su concepción creacionista: la verdad creada, y entonces inteligible, puede conocerse en la realidad. En este punto, cuando debe probar la correlación entre la verdad y las verdades, Alipio recurre al símil de Proteo; la afirmación del escepticismo que no es posible conocer la realidad tal cual es (Acad. 3. 20), y que, consecuentemente, no se debe prestar asentimiento a nada, adquiere nuevas posibilidades interpretativas, a partir del símil de Proteo como imagen de la verdad (Bochet, 2009): las transformaciones de Proteo y las dificultades para atraparlo y obtener conocimiento no hablan ya a favor del escepticismo, sino de la noción platónica de participación (Boersma, 2016a: 177-183; Smalbrugge, 1990). Consideramos que este es el sentido del símil que san Agustín enfatiza en orden a la verdad divina: el relato mítico de que únicamente una deidad puede indicar cómo y dónde atrapar a Proteo tiene aquí una lectura filosófica; en efecto, 
el giro nisi indice alicuiusmodi numine (Acad. 3. 11) conlleva la idea de participación divina de la verdad sensible y representa la posibilidad hallar un eco en la naturaleza de la verdad en sí (Boersma, 2016b: 693-694).

Consideramos que, en este punto, san Agustín expresa su punto de acuerdo con el escepticismo: no es posible un conocimiento absoluto de la materia, sino solo de aquello que es estable o la sabiduría que existe en Dios; en términos del símil: dedicar la vida a alcanzar el conocimiento absoluto de lo sensible es tan vano como intentar asir a Proteo, pues la naturaleza como la deidad marina están en cambio, es más, son el cambio mismo. El elogio de san Agustín a su discípulo Alipio nos coloca en el punto crítico del diálogo: no ha deseado alcanzar otra cosa que este punto firme (Bene habet, inquam, prorsus nibil amplius optaui; acad. 3. 12). San Agustín transforma la hipótesis de Alipio es aseveración, pues, en definitiva, solo una deidad, un numen, puede conducir a la verdad. De aquí surge la exclamación de san Agustín, según la cual Proteo, una representación mítica, nos conduce "al género óptimo de filosofía" (in optimum philosophiae genus! Acad. 3. 13). ¿Cuál es su significado en este contexto? Una imagen, en cuanto expresa materialidad, no es permanente, pero acerca a la verdad eterna: buscar en el orden finito sin contemplación, es decir, sin auxilio de "un cierto numen", es exponerse a ser eludido continuamente por Proteo. Para san Agustín, fiel a la tradición platónica, una imagen es verdadera cuando participa de la verdad eterna. Proteo expresa, en términos míticos, la confianza de que lo mudable únicamente puede ser asido por la contemplación.

El núcleo de la argumentación agustiniana descansa en que las imágenes, para propiamente ser en el grado que les corresponde, están condicionadas por formas que no pueden ser apariencias: la refutación del escepticismo da su primer paso confirmándolo en su ausencia de certezas (Acad. 3. 11); al igual que Proteo, no puede ser atrapado en el mundo sensible, pues en él no hay permanencia para un juicio estable: solo una deidad (la contemplación de las verdades eternas) puede dar consistencia a la mente en el camino de conocer las cosas como son.

\section{CONCLUSIONES}

En nuestro trabajo se ha seguido el modo en que san Agustín colocó los cimientos de un nuevo modelo de racionalidad, desde que incorporó la duda sobre el valor de las imágenes y representaciones como el primer momento del filosofar, que ya podemos calificar de "cristiano", conscientes de todas las dificultades que conlleva, al punto de volverse el adjetivo más importante que el sustantivo. 
Durante el tiempo que compartió las convicciones maniqueas, san Agustín tuvo un trato asiduo con relatos acerca de los principios divinos, cuya naturaleza hemos presentado aquí con cierto detalle, que representaban míticamente el origen del universo. El maniqueísmo se expresaba tanto en su comprensión del cosmos cuanto en el trato asiduo con los textos dados por Mani a su comunidad; el progreso en ambas experiencias, que comparten una raíz común en el drama del alma, en la que cohabitan Bien y Mal, llevaría al auditor a la comprensión de la lucha de contrarios; este proceso de interiorización de imágenes implica un saber que abriría las puertas a un cierto creer. Desde el momento en que san Agustín comenzó a dudar sobre la posibilidad de comprender a Dios tal cual es, como prometía el maniqueísmo, se inició al mismo tiempo una irremediable separación de esta doctrina gnóstica.

La imposibilidad de salvar este hiato, que se ampliaba en la medida que buscaba razones para quitarlo de su horizonte, condujo a san Agustín al escepticismo de cuño ciceroniano; la influencia de esta tradición filosófica es altamente significativa en él, aunque paradójica: si bien la confrontación dialéctica buscaba acabar con el escepticismo académico (Acad. 1. 3. 8), pues sofocaba el espíritu de quienes están dispuestos a dedicarse a la filosofía, san Agustín lo incluye en su reflexión filosófica. Por ello, el escepticismo tiene una función positiva, pues considera que esta actitud presupone una intuición de las ideas, es decir, una búsqueda del carácter inteligible de las imágenes y sensaciones que se presentan. La apariencia, en efecto, depende de la forma a partir de la cual se define: lo que parece ser debe, en cuanto tal, depender del ser. Si el escéptico no opta por el silencio (única opción coherente con esta postura epistemológica), cualquier discurso que intente implicará siempre una referencia a la verdad y a su búsqueda; aquí radica —en la interpretación agustiniana - tanto su limitación como un modo eficaz de contribuir a la comprensión del proceso del conocimiento, pues reclama -sin advertirlo- la presencia del ser en la apariencia; para san Agustín significó un modo de asegurar la vía platónica mediante el intento de su negación. $\mathrm{Al}$ adoptar este procedimiento, desarrolló un enfoque sobre el problema de la certeza; de hecho, su aporte puede presentarse en estos términos: la razón puede poner de manifiesto el conjunto de sus capacidades o quedar limitada a su propia estructura de funcionamiento.

El símil de Proteo sostiene plásticamente la búsqueda agustiniana de dar un sentido positivo al escepticismo académico, es decir, que abra la especulación filosófica y no la paralice; su carácter elusivo queda vinculado al sentido neoplatónico de la imagen y expresa la relación de participación entre la verdad y eterna y las verdades temporales y la posibilidad de que 
estas últimas sean conocidas. Gracias al recurso de Proteo, quien es "imagen de la verdad" permite dar una explicación metafísica a lo que antes era solo engaño de los sentidos: de metáfora del escepticismo pasa a significar la participación en sentido platónico.

Esta transformación del escepticismo hace posible la conversión filosófica y religiosa de san Agustín; por ello, su crítica no podía ser reductiva, señalar simplemente un desacuerdo, sino proponer una comprensión real del escepticismo, sus procedimientos y sus objetivos, transformándolo en un paso preliminar en la investigación de la verdad. Quedan abiertas las puertas para la fundamentación de su realismo interiorista, que presentará a partir de otro de sus grandes diálogos, De Magistro.

\section{REFERENCIAS}

Albornoz Olivares, L. M. (2018). De la racionalidad a la credibilidad: La propuesta epistemológica hacia la fe en la Gramática del asentimiento de John Henry Newman. Veritas, (40), 95-120.

Bermon, E. (2009). 'Contra academicos vel de academis' (Retract. I, 1): Saint Augustin et les Academica de Cicéron. Revue des études anciennes, 111, 75-93.

Bochet, I. (2009). Le Statut de l'image dans la pensée augustinienne. Archives de Philosophie, 72(2), 249-269.

Boersma, G. P. (2016a). Augustine's Early Theology of Image. A Study in the Development of Pro-Nicene Theology. Oxford: Oxford University Press.

Boersma, G. P. (2016b). 'Proteus rising from the sea': a note on Proteus in Contra Academicos, The Heythrop Journal, 57(4), 692-696.

Brachtendorf, J. (2008). Augustinus und der philosophische Weisheitsbegriff. En Th. Fuhrer (Hrsg), Die christlich-philosophischen Diskurse der Spätantike: Texte, Personen, Institutionen (pp. 261-274). Stuttgart: Franz Steiner Verlag.

Brown, P. (1969). The Diffusion of Manichaeism in the Roman Empire. The Journal of Roman Studies, 59(1/2), 92-103.

Calabrese, C. C. (2017). Agustín de Hipona y su recepción del mito maniqueo. Contra Epistulam Manichaei quam vocant Fundamenti'. Ilu. Revista de Ciencias de las Religiones, (22), 53-70.

Catapano, G. (ed.). (2011). Agostino. Tutti i Dialoghi. (Introduzione Generale di G. Catapano e traduzioni di M. Bettetini). Firenze: Bompiani.

de Libera, A. (1990). Albert le Grand et la philosophie. Paris: J. Vrin.

Fuhrer, Th. (ed.) (1997). Augustin Contra Academicos (vel de Academicis, Bücher 2 und 3; Einleitung und Kommentar). Berlin/New York: Walter de Gruyter.

García Bazán, F. (2000). Aspectos inusuales de lo sagrado. Madrid: Trotta.

Giuffré Scibona, C. (2001). How Monotheistic Is Mani's Dualism? Once More on Monotheism and Dualism in Manichaean Gnosis. Numen, 48(4), 444-467.

Goutierre, M-D (2009). La importancia del fin, causa de las causas. Hacia una teología viva y contemplativa en la escuela de santo Tomás. Scripta Theologica, 41(2), 351-375. 
Grant, E. (1986). Science and Theology in the Middle Ages. En C. D. Lindberg \& R. L. Numbers (Eds.), God and Nature. Historical Essays on the Encounter between Christianity and Science (pp. 49-75). Berkeley/Los Angeles/London: University of California Press.

Harding, B. (2003). Skepticism, Illumination and Christianity. In Augustine's Contra Academicos. Augustinian Studies, 34(2), 197-212.

Harding, B. (2006). Epistemology and Eudaimonism in Augustine's Contra Academicos. Augustinian Studies, 37(2), 247-271.

Holte, R. (1962). Béatitude et Sagesse: Saint Augustine et le problème de la fin de l'homme dans la philosophie ancienne. Paris: Études Augustiniennes.

Kenyon, E. (2018). Augustine and the Dialogue. Cambridge: Cambridge University Press.

Kirwan, Ch. (1983). Augustine against the Skeptics. En M. Burnyeat (Ed.), The Skeptical Tradition (pp. 205-223). Berkeley: University of California Press.

Koenen, L. (1978). Augustine and Manichaeism in Light of the Cologne Mani Codex. Illinois Classical Studies, 3, 154-195

Mathews, A. W. (1980). The Development of St. Augustine from Neoplatonism to Christianity, 386-391 AD. Washington, DC: University Press of America.

Mendoza, J. M. F. (2018). Tomás de Aquino y la relación entre filosofía y teología: una interpretación literal de la Suma de Teología I, q.1, a.1. Universitas Philosophica, 35(70), 131-149.

Moreschini, C. (2013). Storia del pensiero cristiano tardo-antico. Milano: Bompiani.

Neiman, A. M. (1982). The Arguments of Augustine's Contra Academicos. The Modern Schoolman, 59(4), 255-279.

Polotsky, H. J. (1996). Il manicheismo. Gnosi di salvezza tra Egitto e Cina. (Leurini, C., Trad.). Rimini: Il Cerchio.

Smalbrugge, M. (1990). La notion de la participation chez Augustin: quelques observations sur le rapport christianisme-platonisme. Augustiniana, 40(1/4), 333-347.

van Lindt, P. (1992). The names of Manichaean mythological figures: a comparative study on terminology in the Coptic sources. Wiesbaden: Otto Harrassowitz Verlag.

van Oort, J. (2008). The Young Augustine's Knowledge of Manichaeism: An Analysis of the Confessiones and Some Other Relevant Texts. Vigiliae Christianae, 62(5), 441-466.

van Oort, J. (2010), Manichaean Christians in Augustine's Life and Work. Church History and Religious Culture, 90(4), 505-546.

Velásquez, Ó. (2007). La iluminación agustiniana como explicación de los contenidos de la mente. Teología y Vida, 48(2/3), 215-227.

Wills, B. N. (2003). The conversion of skepticism in Augustine's Against the Academics. Thesis for the Degree Doctor of Philosophy. Hamilton, Ontario: McMaster University. Disponible en https://macsphere.mcmaster.ca/handle/11375/15817 
Sección TeOlogíA 